\title{
From $\mathrm{PbI}_{2}$ to $\mathrm{MAPbI}_{3}$ through Layered Intermediates
}

Giovanna Pellegrino ${ }^{1}$, Stefania D’Angelo ${ }^{2}$, Ioannis Deretzis ${ }^{1}$, Guglielmo Guido Condorelli ${ }^{2}$, Emanuele Smecca ${ }^{1}$, Graziella Malandrino ${ }^{2}$, Antonino La Magna ${ }^{1}$ and Alessandra Alberti ${ }^{1 *}$

${ }^{1}$ CNR-IMM Zona Industriale, VIII Strada, No. 5, 95121 Catania, Italy

${ }^{2}$ Dipartimento Scienze Chimiche, Università degli studi di Catania and INSTM UdR Catania, V.le A. Doria 6, 95125 Catania, Italy

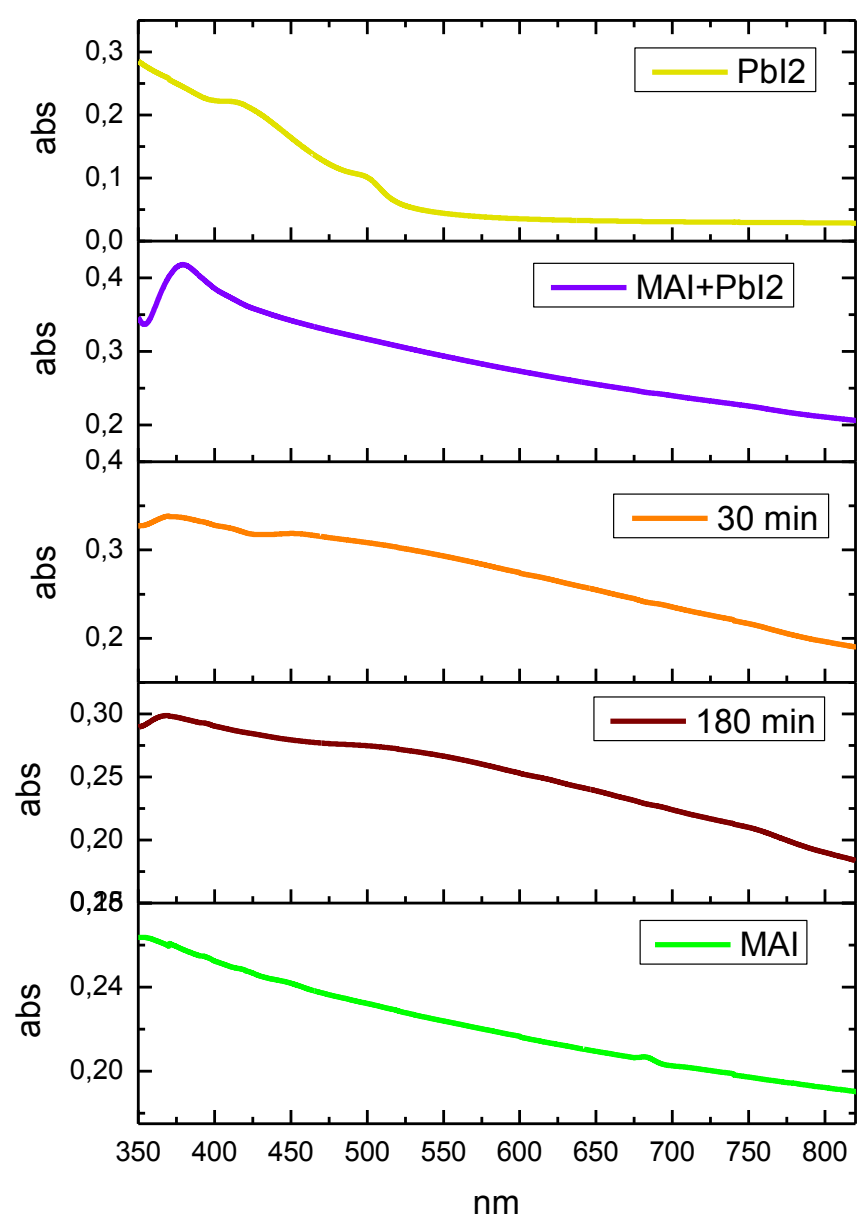

Figure S1 Spectra obtained by subtracting the $\mathrm{TiO}_{2}$ contribution from the data: $(-) \mathrm{PbI}_{2} / \mathrm{TiO}_{2}$; $(-) \mathrm{MAI} / \mathrm{TiO}_{2} ;(-)$ layer after MAI $\left(5 \times 10^{-2} \mathrm{M}\right)+\mathrm{PbI}_{2}$ reaction; sample (-) after (-)30 min and (-)180 min of annealing at $100^{\circ} \mathrm{C}$ 


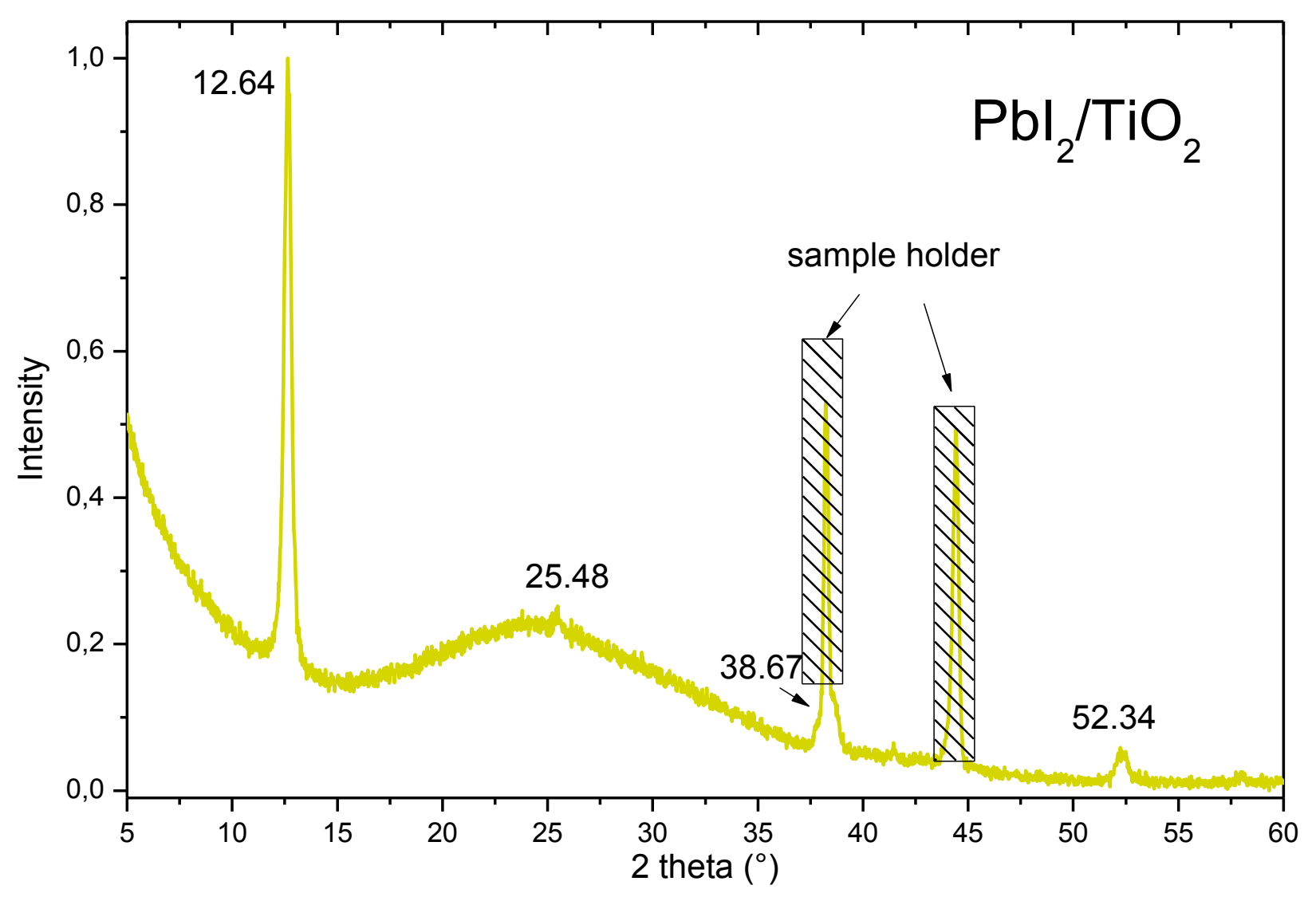

Figure S2 Long range X-ray Diffraction pattern of $\mathrm{PbI}_{2}$ deposited on the $\mathrm{TiO}_{2}$ substrate

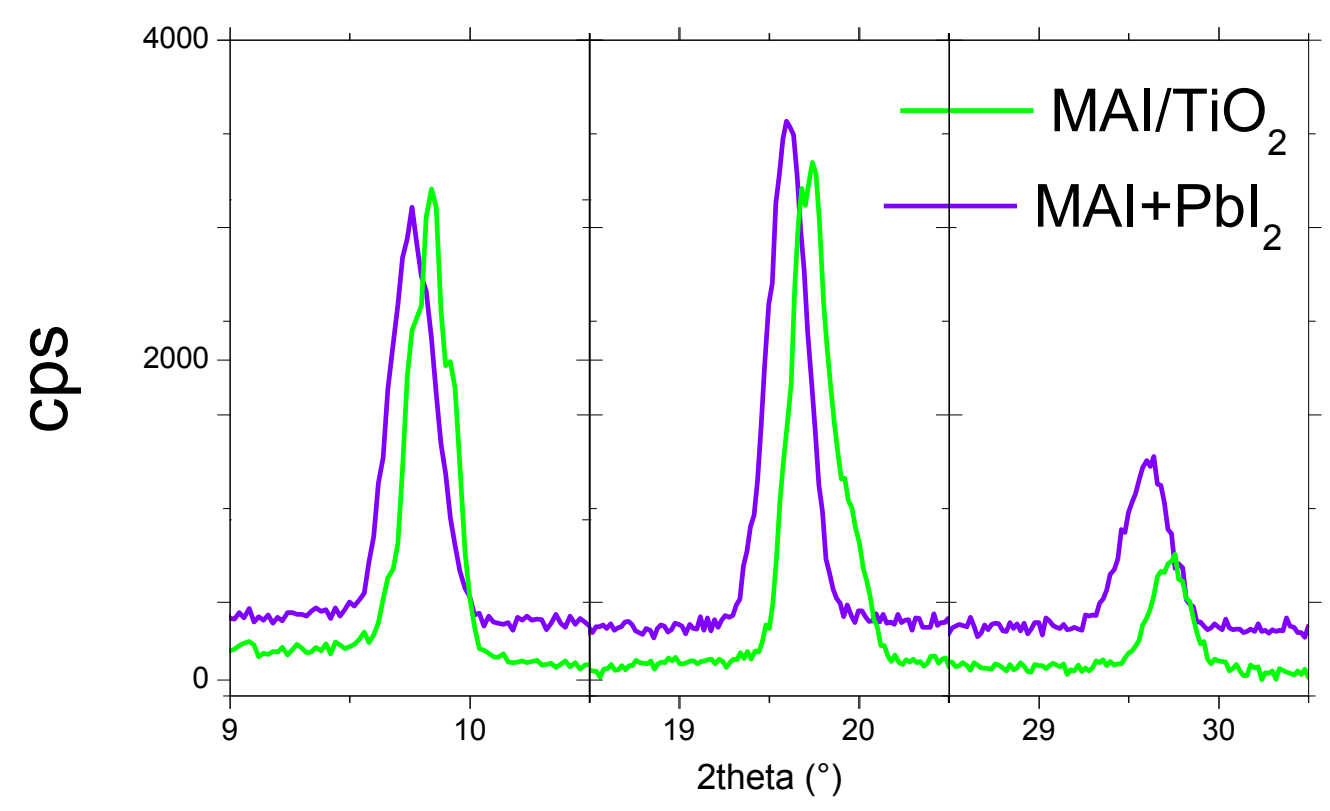

Figure S3 Comparison between the X-ray Diffraction patterns of MAI on the $\mathrm{PbI}_{2} / \mathrm{TiO}_{2}(-)$ and $\mathrm{MAI} / \mathrm{TiO}_{2}$ (-) samples in the diagnostic angular range of the (001) MAI planes. 